\title{
Mensurando a sustentabilidade ambiental: uma proposta de índice para o Mato Grosso do Sul
}

\author{
Measuring environmental sustainability: an index proposal for Mato Grosso do Sul
}

Mesure la durabilite environnementale: uma indice pour Mato Grosso do Sul

Medición de la sostenibilidad del medio ambiente: una propuesta de índice para el Mato Grosso do Sul

Marlos da Silva Pereira*

(marlos.pereira@ufms.br)

Leandro Sauer*

(leandrosauer@uol.com.br)

Mayra Batista Bitencourt Fagundes*
(mayrabitencourt@yahoo.com.br)

Recebido em 23/04/2015; revisado e aprovado em 28/10/2015; aceito em 12/11/2015 DOI: http://dx.doi.org/10.20435/1984042X2016215

Resumo: Este artigo apresenta uma metodologia para se calcular quantitativamente a sustentabilidade ambiental, através de um índice construído com base em diversos outros utilizados nacional e internacionalmente. Para tanto, faz-se um resgate conceitual do desenvolvimento sustentável e seu viés ambiental e da teoria dos indicadores, para apresentar outros índices e construir uma proposta de Índice de Sustentabilidade Ambiental para o estado de Mato Grosso do Sul.

Palavras-chave: sustentabilidade ambiental; indicadores; zoneamento ecológico-econômico.

Abstract: This paper presents a methodology to estimate quantitatively the environmental sustainability through an index built based on several other indexes used nationally and internationally. Therefore, it has a rescue of the conceptual sustainable development and its environmental face and the theory of indicators, to finally introduce other indexes and build a proposal for the Environmental Sustainability Index for Mato Grosso do Sul state.

Key words: environment sustainability; indexes; ecological-economic zoning.

Résumé: Ce article présente une méthodologie pour calculer quantitativement lá durabilité environnementale par un indice construit sur la base em divers autres utilisés nationale et internationale. Pour de faire, de fait une sauvetage conceptuel du développement durable et son biais environnementale de la théorie des indicateurs, pour présenter autres indices et construire une proposition de Indice Durabilité Environnementalepour le état de Mato Grosso do Sul.

Mots-clés: durabilite environnementale; indicateurs; écologique économique zonage.

Resumen: Este trabajo presenta una metodología para el cálculo cuantitativo de la sostenibilidad ambiental, través de un índice construido basado en diversos otros índices utilizados a nivel nacional e internacional. Para eso, se hace un rescate del concepto de desarrollo sostenible y su lado ambiental y la teoría de los indicadores, para entonces presentar otros índices y construir una propuesta de Índice de Sostenibilidad Ambiental el estado de Mato Grosso do Sul.

Palabras-clave: sostenibilidad ambiental; indicadores; zonificación ecológica-económica.

\section{INTRODUÇÃO}

O conceito de desenvolvimento sustentável tem entendimento construído após diversos encontros e reuniões entre líderes e estudiosos mundiais, que objetivaram a geração de novas tecnologias e conhecimentos que auxiliem a continuidade da vivência da raça humana, sem prejuízo ao estilo (qualidade) de vida. Um dos vértices desse macroconceito é o ambiental, que destarte será denominado sustentabilidade ambiental, ou desenvolvimento ambiental sustentável.
Para verificar se os conceitos de desenvolvimento ambiental sustentável estão sendo aplicados e se são eficientes e eficazes, faz-se mister utilizar uma forma racional e lógica para sua mensuração. Nesse sentido, deve ser estudada a doutrina dos indicadores, sendo esta uma maneira mais adequada para as mensurações a se efetuarem.

Para aumentar o conhecimento sobre as formas de mensurar o desenvolvimento ambiental sustentável, efetuar-se-á um compêndio acerca dos índices e indicadores correlacionados e já existentes.

* Universidade Federal de Mato Grosso do Sul (UFMS), Campo Grande, Mato Grosso do Sul, Brasil. 
Por fim, será apresentada uma metodologia para se calcular quantitativamente a sustentabilidade ambiental adaptada ao estado de Mato Grosso do Sul, que é o objetivo deste trabalho: construir o Índice de Sustentabilidade Ambiental (ISA).

\section{PROCEDIMENTOS METODOLÓGICOS}

Esta pesquisa pode ser classificada como hipotética-dedutiva, pois o fenômeno existe e continuará a ocorrer, não obstante a interferência do pesquisador (VERGARA, 2008 , p. 84). Esse entendimento coaduna com o que preconiza Collis e Hussey (2005, p. 27), quando trata da lógica da pesquisa que, neste caso, será dedutiva, pois já existe cabedal teórico a ser estudado, e a parte da pesquisa em si obedecerá aos parâmetros vislumbrados no referencial teórico.

Esta pesquisa também pode ser classificada, quanto aos meios, com foco bibliográfico-documental (VERGARA, 2004, p. 48), pois realiza-se um trabalho bibliográfico, ou seja, levantamento do que já foi estudado acerca das temáticas em questão.

\section{DESENVOLVIMENTO SUSTENTÁVEL}

O conceito de desenvolvimento sustentável é bastante recente. Para Sachs (2002, p. 47-48), a preocupação com a questão ambiental, também inclusiva no desenvolvimento sustentável, é mais recente ainda: seus pressupostos foram a possibilidade de dizimar toda a espécie de vida do planeta (efeito psicológico da Bomba Atômica da Segunda Guerra Mundial) e o paradoxo da conquista do espaço ${ }^{1}$ (mais especificamente o pouso em solo lunar e retorno seguro à Terra). Com isso, ficou claro o quanto este planeta era finito em espaço físico e, principalmente, em recursos naturais. $\mathrm{O}$ "capital natureza" era limitado,

\footnotetext{
${ }^{1} \mathrm{O}$ paradoxo deste caso se deve ao fato de, após a possibilidade se ver o planeta do lado de fora, como uma pequena esfera azulada, perceber-se o quanto este planeta é limitado e seus recursos finitos. Por outro lado, a Corrida Espacial mostrou que a Terra não será, necessariamente, nossa única moradia e que será possível, num eventual cataclismo, ocorrer a migração da raça humana para outros planetas/satélites devidamente adaptados à vida humana. Entretanto tudo isso ainda é ficção.
}

e algumas agressões ao meio ambiente são "depósitos" não passíveis de "resgate".

Nessa sequência, na década de 1970 ocorreram diversos encontros entre as lideranças mundiais com pauta sobre o meio ambiente, e que influenciaram a evolução da construção do conceito de desenvolvimento sustentável, cuja definição varia de acordo com o contexto no qual se insere, como afirma Becker (1993, p. 128): “o conceito de desenvolvimento sustentável não é claro; [...]. Só pode, pois, ser compreendido no contex to histórico da nova ordem em construção sob a desordem global e do desafio que representa [...]".

Todavia o conceito oficial, utilizado como subsídio para a maioria dos trabalhos é a definição apresentada pela Comissão Mundial sobre Meio Ambiente e Desenvolvimento - CMMAD (1991), no trabalho intitulado "Nosso futuro comum" (Relatório Brundtland) fruto da Reunião ocorrida em 1987, segundo o qual o desenvolvimento sustentável é aquele que atende as necessidades do presente, dentro dos limites ecológicos, aumentando a produção e a qualidade de vida, sem detrimento do atendimento às necessidades das gerações futuras.

Esta é a definição considerada mais completa, por abranger os vieses do crescimento econômico (aumento de produção), direitos humanos (aumento da qualidade de vida), meio ambiente (aumentando a produção e a qualidade de vida), adaptabilidade e longo prazo/continuidade (atende as necessidades do presente sem detrimento do atendimento às necessidades das gerações futuras). Outrossim, também é considerada a principal por ser uma marco legal na conceituação do desenvolvimento sustentável.

\subsection{A relação antagônica entre meio ambiente e desenvolvimento sustentável}

Para Buarque (1993, p. 97-98), historicamente, a busca da eficiência econômica se dá à custa do consumo de recursos naturais, ignorando que esses recursos são escassos e, via de regra, de difícil recuperação.

De fato, "o crescimento é uma condição necessária, mas de forma alguma suficiente (muito menos é um objetivo em si mesmo), para se alcançar a meta de uma vida melhor, mais feliz e mais completa para todos" (SACHS, 2008, p. 13). O que o autor 
quis esclarecer é que o crescimento econômico não é o fim, e sim o meio para obter o objetivo comum de "viver mais e melhor". O "crescimento pelo crescimento" não encontra alicerce seguro para enfrentar e superar os questionamentos e demandas que surgirem.

Essa relação "desenvolvimento e meio ambiente" é assaz controversa e, no âmbito deste conflito ideológico, Amstalden (1991) alerta para a necessidade de se achar um denominador comum entre meio ambiente e crescimento econômico e quanto à interdependência de ambos, ao afirmar que "a deterioração do meio ambiente compromete a qualidade de vida e as condições de produção, ameaçando nos dias de hoje a própria continuidade do processo produtivo".

Embora haja conflito aparente, os sistemas econômico e ecológico não são conflitantes. Na verdade, "os sistemas econômicos dependem, para a sua sobrevivência, dos sistemas ecológicos" (SACHS, 1993, p. 36), confirmando o proposto por Amstalden (1991).

De fato, é crucial entendermos que o real crescimento "propõe ações que explicitam a necessidade de tornar compatível a melhoria nos níveis e qualidade de vida com a preservação ambiental" (JACOBI, 1999).

\section{INDICANDO O CAMINHO A SEGUIR: O ESTUDO DOS INDICADORES}

Os indicadores são essenciais quando se pretende representar, de forma objetiva, racional e lógica, uma realidade específica em um determinado período de tempo. Belloni, Magalhães e Sousa (2007, p. 72) consideram que os indicadores servem para "explicitar alguns critérios operacionais, de forma a permitir a análise da política, considerando as dimensões relativas a concepção, formulação, gestão e resultados".

Depreende-se que os autores tencionaram qualificar os indicadores como um espelho da realidade, refletindo de forma fiel a situação. $\mathrm{Ou}$, sendo mais preciso ainda, os indicadores seriam como uma fotografia ${ }^{2}$, que permite uma visão geral, ainda que reduzida a poucos parâmetros, mas que seja passível de utilização e análise para a tomada de decisão.

Os indicadores possibilitam a conversão de um conceito abstrato em diversos subitens práticos e tangíveis. Para exemplificar, pode-se utilizar a sustentabilidade ambiental, que é um tema aparentemente subjetivo, abstrato. Todavia, se se pensar que a sustentabilidade ambiental pode ser dividida em grandes temas (biodiversidade, solo, disponibilidade de recursos hídricos e ar) e que cada um deles possui variáveis mensuráveis, o macroconceito anterior - sustentabilidade ambiental - se torna objetivo, pois passa a ser um conceito subdividido em itens passíveis de aferição.

Em resumo, os indicadores objetivam: explicitar uma realidade em análise, fornecendo subsídios para sua explicação; auxiliar na função controle, permitindo o monitoramento da realidade estudada; transformar leituras qualitativas, abstratas e subjetivas em análises quantitativas, concretas e objetivas, facilitando a compreensão e permitindo a medição, mantendo sua linha de orientação; e apresentar-se como medida padronizada.

\subsection{Classificação e características}

Uma das características essenciais dos indicadores para sua funcionabilidade é a identidade numérica. Sem essa faceta quantitativa, os indicadores são mais subjetivos e podem perder, inclusive, sua aplicabilidade. A subjetividade contida em um indicador qualitativo pode conduzir a análise para o limbo do viés da percepção.

Os autores e as características estudados estão descritos no quadro a seguir: 


\begin{tabular}{|c|c|c|}
\hline Teórico & Propriedade & Característica \\
\hline Januzzi (2009) & Relevância & \multirow{2}{*}{$\begin{array}{c}\text { Representatividade do indicador para o que se deseja } \\
\text { auferir }\end{array}$} \\
\hline $\begin{array}{c}\text { Ripsa (2008) } \\
\text { Cardoso (1999) }\end{array}$ & Específicos & \\
\hline Januzzi (2009) & \multirow{3}{*}{ Validade } & \multirow{3}{*}{ Permitem a medição do que se quer determinar } \\
\hline Ripsa (2008) & & \\
\hline Cardoso (1999) & & \\
\hline Januzzi (2009) & \multirow{3}{*}{ Confiabilidade } & \multirow{3}{*}{ Aplicabilidade em diversas e distintas medições } \\
\hline Ripsa (2008) & & \\
\hline Cardoso (1999) & & \\
\hline Januzzi (2006) & \multirow{2}{*}{ Desagregabilidąde } & \multirow{2}{*}{$\begin{array}{l}\text { Divisão/aglutinação de indicadores em grupos } \\
\text { específicos conforme o interesse do pesquisador }\end{array}$} \\
\hline Ripsa (2008) & & \\
\hline Januzzi (2006) & \multirow{2}{*}{ Historicidade } & \multirow{2}{*}{$\begin{array}{l}\text { Capacidade de comparação do indicador atual com suas } \\
\text { "versões" anteriores }\end{array}$} \\
\hline Ripsa (2008) & & \\
\hline$\frac{\text { Januzzi (2006 e 2009) }}{\text { Ripsa (2008) }}$ & \multirow{2}{*}{ Periodicidade } & \multirow{2}{*}{$\begin{array}{l}\text { Divulgação das variáveis e cálculo do indicador a cada } \\
\text { período definido de tempo }\end{array}$} \\
\hline Cardoso (1999) & & \\
\hline
\end{tabular}

Quadro 1 - Quadro-resumo das propriedades essenciais que os indicadores devem possuir. Fonte: Elaborado pelo autor.

Um dos objetivos que se pretende obter é "que os indicadores possam ser analisados e interpretados com facilidade, e que sejam compreensíveis pelos usuários da informação" (RIPSA, 2008, p. 13). Assim, todo e qualquer observador que analisar um indicador deve facilmente compreender e entender a leitura que foi feita.

Outro fator que Januzzi (2009) coloca e que deve ser levado em consideração depende do bom senso do analista dos indicadores. Não se deve investir excessivo tempo no diagnóstico apresentado pela ferramenta. Caso isso ocorra, o indicador não está cumprindo sua missão de esclarecer, revelar, explicar uma realidade de forma fácil e inteligível.

\subsection{Construção de indicadores}

Para RIPSA (2008, p. 13), “a construção de um indicador é um processo cuja complexidade pode variar desde a simples contagem [...], até o cálculo de proporções, razões, taxas ou índices mais sofisticados", cabendo ao pesquisador constatar o que ele precisa para atingir suas metas.

Para se construir um indicador, é necessário ter em mente o que se deseja obter com ele, para também escolher corretamente quais dados deverão ser levantados e, ainda mais, se os dados essenciais são passíveis de mensuração.

\subsubsection{Definição de um objetivo programático}

O primeiro passo da construção de um indicador é definir o objetivo programático. Ter em mente o que se deseja é essencial para consolidar o indicador com uma boa base conceitual. Muitos objetivos iniciais podem ser impossíveis de medir, mas se forem devidamente estudados e compreendidos, é possível fazer uma conversão, destrinchando-o em algo mensurável, que pode ser chamado de “dimensões analíticas” (JANUZZI, 2009, p. 25).

\subsubsection{Decomposição do objetivo em dimensões analíticas}

Tendo definido o objetivo programático, deve-se decompô-lo para verificar quais dimensões de análise formam sua base conceitual. Existem dois pontos importantes nesta etapa da construção dos indicadores. Um é que é mister verificar quais são todas as dimensões possíveis para se compor o objetivo $^{3}$. O outro ponto importante é que, embora se deva verificar todas as dimensões possíveis, só devem prosseguir na construção do indicador aquelas que sejam relevantes para o alcance do objetivo, ou seja, aquelas que sejam essenciais detalhar.

Por esse motivo, o bom senso do pesquisador e um estudo para aprofundar o conhecimento do assunto são essenciais para a construção de um bom indicador.

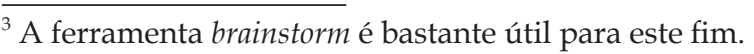


4.2.3 Convergência das dimensões analíticas em dados

Até este ponto, depende-se somente do bom senso e do conhecimento dos pesquisadores que visam à construção de um indicador. A partir desse item, há a necessidade de coleta de dados que sejam convergentes, ou seja, que tenham ligação direta com as dimensões às quais se propõem detalhar.

Essa busca pode ser feita de duas formas: a primeira (e mais fácil) é através da pesquisa em dados já existentes, ou seja, a base de dados da pesquisa é chamada de secundária, pois provém de dados já coletados por outrem, sendo eles instituições públicas ou privadas de pesquisa ou órgãos governamentais.

Já a pesquisa que se utiliza de dados primários é aquela na qual o pesquisador junto com a sua equipe (se ela existir), tendo já identificado as variáveis/fenômenos, selecionam as amostras e os tipos de dados necessários, escolhe método de coleta adequado, aplicam o pré-teste (piloto), adéquam o método de coleta, vão a campo para a coleta das informações, compilam tais dados e chegam ao resultado final (COLLIS; HUSSEY, 2005, p. 146). Todas essas etapas já foram executadas, no caso dos dados secundários.

Tendo encerrado essa etapa, pode-se dizer que se tem um indicador, ou um grupo de indicadores que deverão atender as exigências das dimensões analíticas levantadas.

\section{PROPOSTAS EXISTENTES PARA MENSURAR A SITUAÇÃO DO MEIO AMBIENTE}

Para se construir o Índice de Sustentabilidade Ambiental (ISA) e compreender a forma de medir a sustentabilidade ambiental, efetuou-se o levantamento teórico com vistas a buscar o atual estado da arte. Nesse sentido, a seguir são apresentados os índices que trazem a perspectiva de mensurar o desenvolvimento sustentável. Ainda que alguns desses índices abranjam outras temáticas que não sejam do contexto ambiental, devido ao objetivo deste trabalho, será apresentada apenas a contextualização do foco ambiental dos índices estudados.

\subsection{Environmental Performance Index (EPI)}

O Environmental Performance Index (Índice da Performance Ambiental) é um índice proposto pelas Universidades de Yale ${ }^{4}$ e Columbia ${ }^{5}$, ambas dos Estados Unidos, o qual faz a medição, em nível mundial, de como está a questão ambiental em diversos países ${ }^{6}$, elaborando um ranking que aponta em quais países o meio ambiente está mais adequado ao desenvolvimento sustentável. É produzido com vistas a oferecer subsídios para as políticas públicas. O EPI vem sendo publicado desde 2006, a cada biênio, sendo uma derivação do ESI, que será visto a seguir. Esse índice faz a comparação se houve progresso/regresso na questão ambiental em cada país analisado, e encontra-se em sua quarta edição (2012).

\subsection{Environmental Sustainability Index (ESI)}

O Environmental Sustainability Index (Índice de Sustentabilidade Ambiental) é o predecessor do EPI, tendo o mesmo objetivo, sendo, entretanto, um índice menos abrangente em suas dimensões analíticas. Ressaltase que este índice abrangeu 146 países em sua última edição (2005). Os autores afirmam não ser possível fazer comparações com a edição anterior (2002), pois a metodologia foi altera$\mathrm{da}$, sendo este outro ponto que colaborou para tornar mais oportuna a criação de um novo índice (o EPI). Todavia é importante a análise deste índice, que denota o que era considerado importante no início do século XXI.

\subsection{Dashboard of Sustainability - DS}

O Dashboard of Sustainability (Painel da Sustentabilidade) é uma proposta elaborada pelo International Institute for Sustainable Development (IISD [Instituto Internacional para o Desenvolvimento Sustentável]) que se transformou em um freeware ${ }^{7}$, cuja meta é demonstrar como está a situação do desenvolvimento sustentável nos países do globo

\footnotetext{
${ }^{4}$ http://www.yale.edu/envirocenter.

${ }^{5}$ http:// ciesin.columbia.edu.

${ }^{6}$ Em 2012, abordou 132 países.

${ }^{7}$ Programa de computador sem custos para aquisição e utilização.
} 
terrestre, cujo método adotado é apresentar, em um painel, como está avaliada cada variável de uma dimensão analítica relacionada ao desenvolvimento sustentável, utilizando-se de cores diferenciadas para cada situação (de vermelho escuro - situação crítica, a verde escuro - situação excelente). Dessa forma, é mais fácil vislumbrar os países onde a situação é crítica, além de ser possível fazer comparações diversas.

\subsection{Objetivos de Desenvolvimento do Milênio (ODM)}

Os Objetivos de Desenvolvimento do Milênio é um consenso definido pelas lideranças mundiais no ano de 2000, através da Declaração do Milênio (PNUD, 2000), em reunião do Programa das Nações Unidas para o Desenvolvimento (PNUD), atribuindo diversas metas a serem atingidas até 2015, por todos os países signatários da ONU. Os oito objetivos do milênio podem ser tratados como grandes índices independentes uns dos outros, sendo que cada um deles se desdobra em dimensões analíticas passíveis de serem analisadas.

\subsection{Barometer of Sustainability (BS)}

O Barometer of Sustainability (Barômetro da Sustentabilidade) é uma ferramenta análoga ao painel da sustentabilidade, ou seja, demonstra, através de uma visualização atrativa, a situação do desenvolvimento sustentável em um determinado lócus. É um índice criado pelos pesquisadores da International Union for Conservation of Nature (IUCN) e do International Development Research Center (IDRC), que aborda duas temáticas: o bem-estar humano e o bem-estar do meio ambiente. Para seus criadores, o foco deste índice é fornecer subsídios a todos os atores envolvidos no desenvolvimento sustentável para que norteiem suas políticas de desenvolvimento alinhando-as à sustentabilidade.

\subsection{Environmental Vulnerability Index (EVI)}

O Environmental Vulnerability Index (Índice de Vulnerabilidade Ambiental) é um índice que retrata a vulnerabilidade ambiental de um país, conforme a interação de diversos agentes naturais (catástrofes naturais). Nesse sentido, funciona como um subsídio aos projetos de prevenção de riscos ambientais e redução de danos materiais/ humanos, tendo em vista que, a priori, é impossível aos seres humanos evitar as catástrofes, sendo possível apenas evitar perdas maiores. Este índice é bastante interessante, tendo em vista seu foco diferenciado, pois não demonstra em que se pode melhorar para uma vida com mais qualidade, e sim demonstra onde se deve melhorar para que a espécie humana não se extinga devido às tormentas da natureza.

Foi elaborado pela Comissão de Geociência Aplicada do Pacífico Sul, integrante do Programa das Nações Unidas para o Meio Ambiente (PNUMA), cuja atuação é em uma área extremamente vulnerável aos efeitos naturais de vulcões, terremotos, maremotos, tsunamis e outras situações que incentivaram os pesquisadores a elaborarem essa proposta de padronização do risco ambiental.

\subsection{Living Planet Report}

O Living Planet Report (Relatório Planeta Vivo) é um documento produzido pela ONG World Wide Fund for Nature (WWF [Fundo Mundial para a Natureza]), que possui um foco mais "catastrófico", tendo em vista não estar diretamente vinculada a nenhuma entidade governamental. Nesse relatório, estão contidas diversas dimensões analíticas para estabelecer o desenvolvimento sustentável do planeta. Esse relatório, assim como o EPI, também é divulgado bianualmente desde 2000, e sua maior contribuição é a criação do Índice Planeta Vivo - IPV, que estabelece análise da biodiversidade do planeta com base na série histórica desde o ano de 1970.

Os estudos feitos pela WWF em cada uma das dimensões analíticas não apenas apresentam dados estatísticos como também contextualizam a situação, fazendo com que a compreensão holística seja maior.

\section{8 Índice de Desenvolvimento Sustentável (IDS)}

O Índice de Desenvolvimento Sustentável é uma iniciativa do Instituto Brasileiro de Geografia e Estatística (IBGE, 
2010) com vistas a espelhar a realidade brasileira nas dimensões ambiental, social, econômica e institucional. Percebe-se que possui uma estrutura análoga à estrutura proposta pela Comissão de Desenvolvimento Sustentável das Nações Unidas e do proposto nos Objetivos de Desenvolvimento do Milênio, considerando que é a proposta nacional para atender a uma demanda global. Assim como o EPI e o Living Planet Report, também é um relatório bianual, tendo sua primeira edição publicada em 2002. Este índice é bastante confiável, considerando a idoneidade do IBGE enquanto instituição de pesquisa.

O IDS também é conhecido por seus indicadores possuírem quatro diretrizes: equidade, eficiência, adaptabilidade e atenção a gerações futuras. Com essas diretrizes, este índice possui indicadores que contemplam as características essenciais de um bom indicador.

\subsection{As principais dimensões analíticas da sustentabilidade ambiental e seus indicadores}

Com base nos estudos efetuados nos itens anteriores, foi efetuada a correlação de cada dimensão analítica dos índices apresentados, para que se torne mais claro quais as dimensões consideradas mais importantes, ou seja, quais as dimensões analíticas que aparecem na maioria dos índices.

Com base na tabela acima, percebe-se que as dimensões analíticas água, biodiversidade, ar e solo foram as quatro mais consideradas para a mensuração do desenvolvimento sustentável no contexto ambiental nos índices estudados:

Tabela 1 - Frequência de citação das dimensões analíticas.

\begin{tabular}{|c|c|c|c|c|c|c|c|c|c|}
\hline Dimensão analítica & EPI & ESI & DS & ODM & BS & EVI & LPR & IDS & Total \\
\hline Água & $\mathrm{X}$ & $\mathrm{X}$ & $\mathrm{X}$ & $\mathrm{X}$ & $\mathrm{X}$ & $\mathrm{X}$ & $\mathrm{X}$ & $\mathrm{X}$ & $\mathbf{8}$ \\
\hline Biodiversidade & $\mathrm{X}$ & $\mathrm{X}$ & $\mathrm{X}$ & $\mathrm{X}$ & $\mathrm{X}$ & $\mathrm{X}$ & $\mathrm{X}$ & $\mathrm{X}$ & $\mathbf{8}$ \\
\hline Ar & $\mathrm{X}$ & $\mathrm{X}$ & $\mathrm{X}$ & $\mathrm{X}$ & $\mathrm{X}$ & & $\mathrm{X}$ & $\mathrm{X}$ & $\mathbf{7}$ \\
\hline Solo & $\mathrm{X}$ & & $\mathrm{X}$ & & $\mathrm{X}$ & $\mathrm{X}$ & $\mathrm{X}$ & $\mathrm{X}$ & $\mathbf{6}$ \\
\hline Pesca & $\mathrm{X}$ & & $\mathrm{X}$ & $\mathrm{X}$ & & $\mathrm{X}$ & $\mathrm{X}$ & & $\mathbf{5}$ \\
\hline Florestas & $\mathrm{X}$ & & $\mathrm{X}$ & $\mathrm{X}$ & & & $\mathrm{X}$ & & $\mathbf{4}$ \\
\hline Mudança climática e energia & $\mathrm{X}$ & & $\mathrm{X}$ & & & $\mathrm{X}$ & $\mathrm{X}$ & & $\mathbf{4}$ \\
\hline Agricultura & $\mathrm{X}$ & & $\mathrm{X}$ & & & $\mathrm{X}$ & & & $\mathbf{3}$ \\
\hline Saúde e meio ambiente & $\mathrm{X}$ & & & $\mathrm{X}$ & & & & & $\mathbf{2}$ \\
\hline Utilização de recursos & & & & & $\mathrm{X}$ & & $\mathrm{X}$ & & $\mathbf{2}$ \\
\hline
\end{tabular}

Fonte: Elaborado pelo autor.

É importante ressaltar que existe a proposta do Zoneamento Ecológico-Econômico de Mato Grosso do Sul (ZEE-MS), que, em sua concepção ideológica, utiliza-se desses quatros índices para construir a sustentabilidade ambiental (MATO GROSSO DO SUL, 2009a, p. 23). Nesse sentido, é mister referendar a proposta do ZEE-MS, quando considera que os grandes temas da sustentabilidade ambiental é a disponibilidade de recursos hídricos (água), a biodiversidade, o ar e o solo.

$\mathrm{Na}$ ordem lógica de mais aparições, temos na sequência: pesca, florestas, mudança climática e energia, agricultura, saúde e meio ambiente e utilização de recursos. Embora todas essas dimensões sejam importantes, com uma análise do relatório Desempenho do Comércio Exterior de Mato Grosso do
Sul - março $/ 2012^{8}$, têm-se as duas maiores exportações ${ }^{9}$ sendo de produtos provenientes da agricultura. Em contraponto, o mesmo relatório apresenta o item "peixes" como um dos mais importados pelo Estado, do que se pode inferir que a pesca não se apresenta como prática estratégica para Mato Grosso do Sul.

Outro ponto importante para ser analisado é que o Estado é dividido em três biomas: cerrado, pantanal e floresta atlântica (MATO GROSSO DO SUL, 2009b, p. 20). Desses, a floresta atlântica ${ }^{10}$ é o menos expressivo, pois, devido à ação antrópica, essa grande flores-

\footnotetext{
${ }^{8}$ Disponível em: <http:/ / www.unisite.ms.gov.br/ unisite/controle/ShowFile.php?id=105789>. Acesso em: 5 jun. 2012.

${ }^{9}$ Em valores financeiros.

${ }^{10}$ Também conhecida como Mata Atlântica.
} 
ta está "confinada a pequenos fragmentos, muito distantes uns dos outros, a maioria em Unidades de Conservação" (MATO GROSSO DO SUL, 2009b, p. 20).

De posse das considerações acima e considerando a inexpressividade das dimensões saúde e meio ambiente e utilização de recursos, elabora-se uma proposta de inclusão, para cálculo do ISA, das variáveis da dimensão analítica agricultura na dimensão analítica solo e inclusão da dimensão analítica mudança climática e energia.

Considerando as cinco dimensões analíticas definidas como importantes para mensurar a sustentabilidade ambiental em Mato Grosso do Sul, quais sejam, água, biodiversidade, ar, solo e mudança climática e energia, será efetuada a análise de quais são as variáveis pertinentes ao cálculo do ISA em cada uma dessas dimensões analíticas.

\subsection{1 Água}

No conceito do ZEE-MS, a água é tratada conceitualmente apenas em seu quesito disponibilidade. Todavia todos os índices verificados foram claros ao referendar que a água deve ser tratada também no seu aspecto de qualidade, indicada para as diversas atividades humanas. Por isso, destarte, será adotado apenas o vernáculo "água" para identificar essa dimensão analítica. Na tabela a seguir, apresentamos os indicadores identificados nos índices estudados:

Tabela 2 - Frequência de citação das variáveis da dimensão analítica água.

\begin{tabular}{|c|c|c|c|c|c|c|c|c|c|}
\hline Variável & EPI & ESI & DS & ODM & BS & EVI & LPR & IDS & Total \\
\hline Acesso à água potável & $\mathrm{X}$ & $\mathrm{X}$ & & $\mathrm{X}$ & & & & $\mathrm{X}$ & $\mathbf{4}$ \\
\hline Acesso à água tratada & $\mathrm{X}$ & & & $\mathrm{X}$ & & $\mathrm{X}$ & & $\mathrm{X}$ & $\mathbf{4}$ \\
\hline Oxigênio dissolvido & & $\mathrm{X}$ & $\mathrm{X}$ & & $\mathrm{X}$ & & & & $\mathbf{3}$ \\
\hline Concentração de fósforo & & $\mathrm{X}$ & $\mathrm{X}$ & & & & & & $\mathbf{2}$ \\
\hline Densidade demográfica na zona costeira & & & & & $\mathrm{X}$ & & & $\mathrm{X}$ & $\mathbf{2}$ \\
\hline Disponibilidade de água de superfície & & $\mathrm{X}$ & & & & & $\mathrm{X}$ & & $\mathbf{2}$ \\
\hline Disponibilidade de água subterrânea & & $\mathrm{X}$ & & & & & $\mathrm{X}$ & & $\mathbf{2}$ \\
\hline Índice de Qualidade das Águas & & & & & $\mathrm{X}$ & & & $\mathrm{X}$ & $\mathbf{2}$ \\
\hline Uso de água renovável & & & $\mathrm{X}$ & & & $\mathrm{X}$ & & & $\mathbf{2}$ \\
\hline Variação na quantidade de água & $\mathrm{X}$ & & & & & & $\mathrm{X}$ & & $\mathbf{2}$ \\
\hline Condutividade elétrica & & $\mathrm{X}$ & & & & & & & $\mathbf{1}$ \\
\hline Partículas sólidas em suspensão & & $\mathrm{X}$ & & & & & & & $\mathbf{1}$ \\
\hline Presença de coliformes fecais & & & $\mathrm{X}$ & & & & & & $\mathbf{1}$ \\
\hline $\begin{array}{c}\text { Proporção do total de recursos hídricos } \\
\text { utilizados }\end{array}$ & & & & $\mathrm{X}$ & & & & & $\mathbf{1}$ \\
\hline
\end{tabular}

Fonte: Elaborado pelo autor.

Estudando aprofundamente o Índice de Qualidade das Águas (IQA), percebe-se que ele faz uso de algumas variáveis para seu cálculo, sendo um indicador sintético cujo cálculo é elaborado utilizando variáveis que são tratadas separadamente em outros estudos. Dessa forma, é mais racional utilizar o IQA, ao invés de suas diversas variáveis em separado.

Outro fator importante para essa avaliação é a relevância da variável para com a análise em questão, consoante Januzzi (2009), a característica de representar adequadamente a informação que se deseja verificar. Para atender a esse mérito, devem ser excluídas as variáveis que tratam da disponibilidade de água, pois são variáveis que atenderão somente à informação de existência de água, seja em superfície ou em lençóis freáticos. Outra condição é que a água é escassa em alguns locais, independente da ação antrópica (áreas desérticas, por exemplo). Dessa forma, tornam-se insubsistentes essas duas variáveis para o que se tenciona calcular. Serão utilizadas as seguintes variáveis para o cálculo da dimensão analítica "água" no ISA, descartando as demais variáveis por serem consideradas inexpressivas ou terem sido incorporadas pelo IQA: acesso à água tratada, acesso à água potável e Índice de Qualidade das Águas. 


\subsubsection{Biodiversidade}

Nesta dimensão analítica, foram iden-

tificadas as seguintes variáveis:

Tabela 3 - Frequência de citação das variáveis da dimensão analítica biodiversidade.

\begin{tabular}{|c|c|c|c|c|c|c|c|c|c|}
\hline Variável & EPI & ESI & DS & ODM & BS & EVI & LPR & IDS & Total \\
\hline Aves ameaçadas & & $\mathrm{X}$ & $\mathrm{X}$ & $\mathrm{X}$ & & $\mathrm{X}$ & $\mathrm{X}$ & $\mathrm{X}$ & $\mathbf{6}$ \\
\hline Mamíferos ameaçados & & $\mathrm{X}$ & $\mathrm{X}$ & $\mathrm{X}$ & & $\mathrm{X}$ & $\mathrm{X}$ & $\mathrm{X}$ & $\mathbf{6}$ \\
\hline Proteção de áreas críticas & $\mathrm{X}$ & $\mathrm{X}$ & & $\mathrm{X}$ & $\mathrm{X}$ & $\mathrm{X}$ & & $\mathrm{X}$ & $\mathbf{6}$ \\
\hline Anfíbios ameaçados & & $\mathrm{X}$ & & $\mathrm{X}$ & & $\mathrm{X}$ & $\mathrm{X}$ & $\mathrm{X}$ & $\mathbf{5}$ \\
\hline Áreas marinhas protegidas & $\mathrm{X}$ & & & $\mathrm{X}$ & & $\mathrm{X}$ & & & $\mathbf{3}$ \\
\hline Proteção do bioma & $\mathrm{X}$ & $\mathrm{X}$ & & & & $\mathrm{X}$ & & & $\mathbf{3}$ \\
\hline Existência de espécies invasoras & & & & & & $\mathrm{X}$ & & $\mathrm{X}$ & $\mathbf{2}$ \\
\hline Índice Nacional de Biodiversidade & & $\mathrm{X}$ & & & & & & & $\mathbf{1}$ \\
\hline Índice Planeta Vivo & & & & & & & $\mathrm{X}$ & & $\mathbf{1}$ \\
\hline
\end{tabular}

Fonte: Elaborado pelo autor.

As variáveis proteção de áreas críticas, proteção do bioma e áreas marinhas protegidas são diferentes focos de uma mesma matéria: áreas de proteção ambiental.

Dessa forma, essas variáveis serão condensadas nessa única variável. O mesmo ocorre com as variáveis aves ameaçadas, mamíferos ameaçados e anfíbios ameaçados, que podem, sem prejuízo para o resultado da pesquisa, serem agrupadas em uma única variável denominada "espécies ameaçadas de extinção". Assim, definem-se as variáveis que comporão esta dimensão: áreas de proteção ambiental, presença de espécies invasoras e espécies ameaçadas de extinção.

A variável presença de espécies invaso- ras foi incluída por sua influência no equilíbrio ambiental, em especial por ser um fator importante na extinção de algumas espécies. As demais variáveis foram desconsideradas, por sua especificidade funcional nos estudos em que foram apresentadas.

\subsection{3 $\mathrm{Ar}$}

Muito embora alguns índices denominem esta dimensão como "atmosfera", optou-se por manter a definição adotada pela equipe do ZEE-MS, principalmente pela facilidade de compreensão que esse termo possibilita. Foram identificadas as variáveis abordadas a seguir.

Tabela 4 - Frequência de citação das variáveis da dimensão analítica ar.

\begin{tabular}{|c|c|c|c|c|c|c|c|c|c|}
\hline Variável & EPI & ESI & DS & ODM & BS & EVI & LPR & IDS & Total \\
\hline Emissão de gases do efeito estufa & & & $\mathrm{X}$ & $\mathrm{X}$ & & & $\mathrm{X}$ & $\mathrm{X}$ & $\mathbf{4}$ \\
\hline Emissão de gás carbônico pelo PIB & & & $\mathrm{X}$ & $\mathrm{X}$ & & & $\mathrm{X}$ & & $\mathbf{3}$ \\
\hline Emissão de gás carbônico per capita & & & $\mathrm{X}$ & $\mathrm{X}$ & & & $\mathrm{X}$ & & $\mathbf{3}$ \\
\hline Partículas inaláveis & $\mathrm{X}$ & $\mathrm{X}$ & & & & & & $\mathrm{X}$ & $\mathbf{3}$ \\
\hline Veículos em uso & & $\mathrm{X}$ & $\mathrm{X}$ & & & $\mathrm{X}$ & & & 3 \\
\hline Emissão de dióxido de enxofre per capita & $\mathrm{X}$ & & & & & $\mathrm{X}$ & & & $\mathbf{2}$ \\
\hline Poluição em locais fechados & $\mathrm{X}$ & $\mathrm{X}$ & & & & & & & $\mathbf{2}$ \\
\hline Razão de veículos por habitante & & & & & $\mathrm{X}$ & $\mathrm{X}$ & & & $\mathbf{2}$ \\
\hline Concentração de dióxido de enxofre & & $\mathrm{X}$ & & & & & & & $\mathbf{1}$ \\
\hline Concentração de dióxido de nitrogênio & & $\mathrm{X}$ & & & & & & & $\mathbf{1}$ \\
\hline Emissão de dióxido de enxofre pelo PIB & $\mathrm{X}$ & & & & & & & & $\mathbf{1}$ \\
\hline
\end{tabular}

Fonte: Elaborado pelo autor. 
Notadamente, esta dimensão apresenta variáveis com bastante dispersão, ou seja, a metodologia que cada índice estudado adotou é diferente devido a pequenos detalhes conceituais. Dessa forma, algumas variáveis podem ser agrupadas, gerando a utilização das seguintes variáveis, para cálculo da dimensão "ar" no ISA, desconsiderando as demais variáveis, considerando a presença menos constante nos índices estudados: emissão de gases do efeito estufa, partículas inaláveis e utilização de veículos.

\subsubsection{Solo}

Alguns índices denominavam esta dimensão como "terra" ou ainda precedido pela palavra "utilização". Todavia, nesta dimensão, também optou-se por manter a denominação adotada no ZEE-MS, com o fim de evitar divergências na compreensão. Outra mudança efetuada foi a inclusão da dimensão analítica agricultura, tendo em vista que é uma questão intimamente ligada à utilização do solo. Assim, passa-se à abordagem das variáveis identificadas.

Tabela 5 - Frequência de citação das variáveis da dimensão analítica solo.

\begin{tabular}{|c|c|c|c|c|c|c|c|c|c|}
\hline Variável & EPI & ESI & DS & ODM & BS & EVI & LPR & IDS & Total \\
\hline Consumo de fertilizante & & $\mathrm{X}$ & $\mathrm{X}$ & & $\mathrm{X}$ & $\mathrm{X}$ & & $\mathrm{X}$ & $\mathbf{5}$ \\
\hline Terras em uso de lavoura & & & & & $\mathrm{X}$ & $\mathrm{X}$ & $\mathrm{X}$ & $\mathrm{X}$ & $\mathbf{4}$ \\
\hline Uso de pesticidas & & & $\mathrm{X}$ & & $\mathrm{X}$ & $\mathrm{X}$ & & $\mathrm{X}$ & $\mathbf{4}$ \\
\hline Áreas desérticas/áridas & & & $\mathrm{X}$ & & & $\mathrm{X}$ & $\mathrm{X}$ & & $\mathbf{3}$ \\
\hline Áreas de reflorestamento & & & $\mathrm{X}$ & & & $\mathrm{X}$ & & & $\mathbf{2}$ \\
\hline Normatização de pesticidas & $\mathrm{X}$ & $\mathrm{X}$ & & & & & & & $\mathbf{2}$ \\
\hline Subsídios à agricultura & $\mathrm{X}$ & $\mathrm{X}$ & & & & & & & $\mathbf{2}$ \\
\hline Terras de pastagens & & & & & & & $\mathrm{X}$ & $\mathrm{X}$ & $\mathbf{2}$ \\
\hline Área natural & & $\mathrm{X}$ & & & & & & & $\mathbf{1}$ \\
\hline Área urbanizada & & $\mathrm{X}$ & & & & & & & $\mathbf{1}$ \\
\hline $\begin{array}{c}\text { População morando em áreas sem } \\
\text { esgotamento sanitário }\end{array}$ & & & & \multirow{2}{*}{$\mathrm{X}$} & & & & & $\mathbf{1}$ \\
\hline $\begin{array}{c}\text { Queimadas e incêndios florestais } \\
\text { Tamanho da área }\end{array}$ & & & & & & $\mathrm{X}$ & & & $\mathbf{1}$ \\
\hline
\end{tabular}

Fonte: Elaborado pelo autor.

Para esta análise, as variáveis terras em uso de lavoura, áreas desérticas/áridas, áreas de reflorestamento, terras de pastagens, área natural e área urbanizada serão agrupadas na variável denominada "condição da terra", por serem facetas diferentes de um mesmo ponto de análise. Normatização e uso de pesticidas também ficarão agrupados. Descartando as demais variáveis devido a pouca frequência de aparição, temos a seguinte definição de variáveis para cálculo da dimensão analítica "solo" no ISA: condição da terra, fertilizantes, pesticidas e subsídios à agricultura.

\subsubsection{Mudanças climáticas e energia}

Devido à influência apresentada na própria publicação do ZEE-MS das mudanças climáticas nas demais dimensões de análise do desenvolvimento ambiental sustentável de Mato Grosso do Sul, e pela frequente consideração dessa dimensão como importante para mensurar a sustentabilidade ambiental, foi efetuada sua inclusão para o cálculo do ISA. 
Tabela 6 - Frequência de citação das variáveis da dimensão analítica mudanças climáticas e energia.

\begin{tabular}{|c|c|c|c|c|c|c|c|c|c|}
\hline Variável & EPI & ESI & DS & ODM & BS & EVI & LPR & IDS & Total \\
\hline Desflorestamento & & & & & & & $\mathrm{X}$ & $\mathrm{X}$ & $\mathbf{2}$ \\
\hline Energia renovável & $\mathrm{X}$ & $\mathrm{X}$ & & & & & & & $\mathbf{2}$ \\
\hline Períodos de seca & & & & & & $\mathrm{X}$ & $\mathrm{X}$ & & $\mathbf{2}$ \\
\hline Emissão de gás carbônico pelo PIB & $\mathrm{X}$ & & & & & & & & $\mathbf{1}$ \\
\hline Emissão de gás carbônico per capita & $\mathrm{X}$ & & & & & & & & $\mathbf{1}$ \\
\hline Emissão de gás carbônico por KWh & $\mathrm{X}$ & & & & & & & & $\mathbf{1}$ \\
\hline Períodos chuvosos & & & & & & $\mathrm{X}$ & & & $\mathbf{1}$ \\
\hline Períodos frios & & & & & & $\mathrm{X}$ & & & $\mathbf{1}$ \\
\hline Períodos quentes & & & & & & $\mathrm{X}$ & & & $\mathbf{1}$ \\
\hline
\end{tabular}

Fonte: Elaborado pelo autor.

Nessa dimensão, aparecem algumas grandes divergências conceituais entre os índices. O EPI considera as diversas facetas de emissão de gás carbônico como um problema de mudança climática, e não poluição do ar como a maioria dos índices. Como é uma variável que será utilizada no cálculo da dimensão " ar", será excluída nesta dimensão analítica. Assim, definem-se as variáveis a seguir para cálculo desta dimensão: energia renovável e áreas desmatadas.

Embora suas variáveis sejam pouco citadas, é interessante persistir no cálculo dessa dimensão para que conste a importância da ação antrópica na mudança climática que, consequentemente, provoca alterações no meio ambiente.

\section{CONSTRUINDO O ÍNDICE DE SUSTENTABILIDADE AMBIENTAL PARA O MATO GROSSO DO SUL}

Apresentam-se no quadro a seguir as dimensões analíticas e suas respectivas variáveis que serão utilizadas no cálculo do Índice de Sustentabilidade Ambiental, adaptadas a Mato Grosso do Sul:

\begin{tabular}{|c|c|c|}
\hline Indicador & Dimensões analíticas & Variáveis \\
\hline \multirow{15}{*}{ 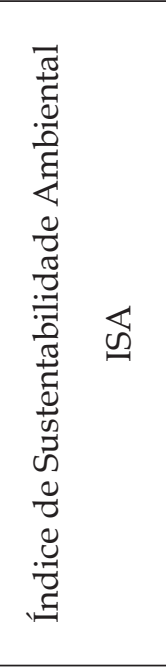 } & \multirow{3}{*}{ Água } & Acesso à água tratada \\
\hline & & Acesso à água potável \\
\hline & & Índice de Qualidade das Águas \\
\hline & \multirow{3}{*}{ Biodiversidade } & Áreas de proteção ambiental \\
\hline & & Presença de espécies invasoras \\
\hline & & Espécies ameaçadas de extinção \\
\hline & \multirow{3}{*}{$\mathrm{Ar}$} & Emissão de gases do efeito estufa \\
\hline & & Partículas inaláveis \\
\hline & & Utilização de veículos \\
\hline & \multirow{4}{*}{ Solo } & Condição da terra \\
\hline & & Fertilizantes \\
\hline & & Pesticidas \\
\hline & & Subsídios à agricultura \\
\hline & \multirow{2}{*}{ Mudanças climáticas e energia } & Energia renovável \\
\hline & & Áreas desmatadas \\
\hline
\end{tabular}

Quadro 2 - Estrutura do Índice de Sustentabilidade Ambiental - ISA.

Fonte: Elaborado pelo autor. 


\section{CONSIDERAÇÕES FINAIS}

Consoante ao objetivo deste trabalho, foi apresentada uma proposta para o ISA, adaptada à realidade sul-mato-grossense, para que se possa medir em que nível se encontra a sustentabilidade ambiental no Estado.

Todavia é essencial frisar que este estudo necessita ser aprofundado para evidenciar qual a forma de medição de cada variável, bem como verificar se cada uma das variáveis é positiva ou negativa (se quanto maior, melhor, ou se quanto menor, pior). Também é mister analisar se as variáveis possuem as características consideradas essenciais para um bom indicador, tornando esta proposta passível de utilização prática.

Outro ponto crucial a ser desencadeado após este estudo é a verificação da disponibilidade das informações - considerando uma pesquisa com dados secundários - se há dados para Mato Grosso do Sul (ou suas regiões ou municípios), ou se é factível apenas testar essa metodologia em um nível macro (CentroOeste ou Brasil) para, posteriormente, sugerir alterações, ou ainda, realizar a coleta dos dados primários necessários para atingir o objetivo proposto.

\section{REFERÊNCIAS}

AMSTALDEN, L. F. F. Os custos socioambientais da modernização agrícola brasileira. Cadernos Monografias [do] Instituto de Filosofia e Ciências Sociais da Unicamp, Campinas, SP, ano I, n. 1, 1991.

BECKER, B. K. A Amazônia pós ECO-92: por um desenvolvimento regional responsável. In: BURSZTYN, Marcel (Org.). Para pensar o desenvolvimento sustentável. São Paulo: IBAMA/ENAP/Brasiliense, 1993. p. 128-143.

BELLONI, I.; MAGALHÃES, H. de; SOUSA, L. C. de. Metodologia de avaliação em políticas públicas: uma experiência em educação profissional. 4. ed. São Paulo: Cortez, 2007. (Coleções Questões da Nossa Época; v. 75).

BUARQUE, C. O pensamento em um mundo Terceiro Mundo. In: BURSZTYN, M. (Org.). Para pensar o desenvolvimento sustentável. São Paulo: IBAMA/ENAP/ Brasiliense, 1993. p. 57-101.

COMISSÃO MUNDIAL SOBRE MEIO AMBIENTE E DESENVOLVIMENTO (CMMAD). Nosso futuro comum. 2. ed. Tradução de "Our common future", 1. ed., 1988. Rio de Janeiro: Editora da Fundação Getúlio Vargas, 1991. Disponível em: <http://www.un-documents.net/ wced-ocf.htm>. Acesso em: $1^{\circ}$ maio 2012.
COLLIS, J.; HUSSEY, R. Pesquisa em administração: um guia prático para alunos de graduação e pós-graduação. Tradução Lucia Simonini. 2. ed. Porto Alegre, RS: Bookman, 2005.

INSTITUTO BRASILEIRO DE GEOGRAFIA E ESTATÍSTICA (IBGE). Indicadores de desenvolvimento Sustentável: Brasil, 2010. Rio de Janeiro, 2010. Disponível em: <http://www.ibge.gov.br/home/geociencias/ recursosnaturais/ids/ids2010.pdf $>$. Acesso em: 30 maio 2012

JACOBI, P. R. Meio ambiente e sustentabilidade. In: CENTRO DE ESTUDOS E PESQUISAS DE ADMINISTRAÇÃO MUNICIPAL (CEPAM). O município no século XXI. São Paulo: CEPAM, 1999. p. 175-184. Disponível em: <http://www.scribd.com/ full/7506458?access_key=key-i2yjzf8buz2iw58y3pt $>$. Acesso em: $1^{\circ}$ maio 2012.

JANUZZI, P. de M. Indicadores socioeconômicos na gestão pública. Florianópolis, SC: Departamento de Ciências da Administração/UFSC; [Brasília]: CAPES/UAB, 2009. 112 p.: il.

MATO GROSSO DO SUL, Governo do Estado de. ZEE-MS - Zoneamento Ecológico-Econômico do Estado: induzindo o desenvolvimento sustentável e a preservação de recursos naturais. Apresentação do Projeto. 2009a. Disponível em: <http://www.semac.ms.gov. br/controle/ShowFile.php?id=18278>. Acesso em: 10 maio 2012

Zoneamento Ecológico-Econômico do Estado de Mato Grosso do Sul. Anexo I da Lei n ${ }^{\circ} 3.839$, de 28 de dezembro de 2009. Diário Oficial - Estado de Mato Grosso do Sul, n. 7.612, Suplemento, Campo Grande, MS, 29 dez. 2009b. p. 3-68.

PROGRAMA DAS NAÇÕES UNIDAS PARA O DESENVOLVIMENTO (PNUD). Declaração do Milênio. 2000. Disponível em: <http://www.unric.org/html/ portuguese/uninfo/DecdoMil.pdf $>$. Acesso em: 30 maio 2012.

REDE INTERAGENCIAL DE INFORMAÇÃO PARA A SAÚDE (RIPSA). Indicadores básicos para a saúde no Brasil: conceitos e aplicações. 2. ed. Brasília: Organização Pan-Americana da Saúde, 2008. 349 p.: il. Disponível em: <http://www.ripsa.org.br/php/level.php?lang= pt\&component=68\&item=20>. Acesso em: 18 dez. 2011.

SACHS, I. Estratégias de transição para o século XXI. In: BURSZTYN, Marcel (Org.). Para pensar o desenvolvimento sustentável. São Paulo: IBAMA/ENAP/Brasiliense, 1993. p. $29-56$.

Caminhos para o desenvolvimento sustentável. Rio de Janeiro: Garamond, 2002. (Coleção Idéias Sustentáveis).

Desenvolvimento: includente, sustentável, sustentado. Rio de Janeiro: Garamond, 2008.

VERGARA, S. C. Projetos e relatórios de pesquisa em administração. 5. ed. São Paulo: Atlas, 2004.

Métodos de pesquisa em administração. 3. ed. São Paulo: Atlas, 2008. 